\title{
Karyological and flow cytometric evidence of triploid specimens in Bufo viridis (Amphibia Anura)
}

\author{
D. Cavallo ${ }^{1}$, R. De Vita ${ }^{1}$, P. Eleuteri ${ }^{1}$, L.Borkin $^{2}$, V. Ermechenko ${ }^{3}$, G. Odierna ${ }^{4}$ and E. Balletto
}

${ }^{1}$ Environmental Department, ENEA C. R. Casaccia, Rome Italy, ${ }^{2}$ Department of Herpetology, Zoological Institute, Russian Academy of Sciences, St. Petersburg, Russian Federation, ${ }^{3}$ Museum Zoology, Institute of Biology and Zoology, Kirgizstan, Russian Federation, ${ }^{4}$ Department of Evolutive and Comparative Biology, University of Naples "Federico II", Italy, and ${ }^{5}$ Department of Animal Biology, University of Turin, Italy

Accepted: 29/11/2001

Key words: DNA content, chromosomes, Bufo viridis, triploidy, flow cytometry, polyploidy

\section{SUMMARY}

Karyological and flow cytometric (FCM) analyses were performed on a group of 14 green toads of the Bufo viridis species from seven Eurasian populations. Both approaches gave concordant results concerning the DNA ploidy level. All the populations examined were represented exclusively by diploid or tetraploid specimens, except one, where triploids were found. Results evidenced an interpopulation variability in DNA content against the same ploidy level, as well as an unusually high number of triploids in a particular reproductive place. The origin of polyploidy and the presence and persistence of a high number of triploids in a particular population are discussed.

\section{INTRODUCTION}

Polyploidy is an important mechanism of evolution in lower vertebrates, particularly in amphibia anura (Olmo et al., 1989), which can increase the nuclear DNA content. In particular, an increase in DNA was found in polyploid anurans without any changes in the level of RNA and protein synthesis with respect to diploid counterparts. Tetraploid, hexaploid or even octoploid species or populations have been described in six anuran families: Pipidae, Hylidae, Leptodactylidae, Myobatrachidae, Ranidae and Bufonidae (King, 1990). In the Bufonidae, tetraploid populations of Bufo viridis, an as yet undefined species, taxonomically (Pisanetz 1978), have been found in Asia. These populations are widespread and mixed with diploid populations along an extensive area from Turkmenistan to Uzbekistan, in Tadjikistan, Kazakhstan, Kirgizstan and Mongolia (Pisanetz 1978, 1991; Roth, 1986; Borkin et al., 1986).

It is still being debated whether the origin of tetraploidy in Bufo viridis is due: 1), autopolyploidy (developed by fusion of two diploid gametes to one tetraploid zygote) 2), to the suppression of the first mitosis following fertilization) (Roth et al.1986) 3), to allopolyploidy (hybridization between two diversified diploid populations and subsequent duplication of two chromosome sets), or 4), to single events of auto-or allopolyploidy which occurring independently in each population (Pisanetz et al.1978).

Correspondence to: R. De Vita

E-mail: devita@casaccia.enea.it 
We report here the results of karyological analysis carried out on samples of Bufo viridis from five Asiatic populations (North Kirgizstan and South Kazakhstan) and two European populations (Moldavia and Italy), by conventional staining and $\mathrm{C}$ banding. We considered it of particular interest to evaluate the ploidy level of the samples from Kokjar (Kirgizstan) because we found there the previous spring diploid and tetraploid individuals as well as several triploid specimens (Odierna et al., 1995). The results of this work will permit us to study an eventual temporal continuity of triploids in a particular reproductive site and, in that case, to propose an explanation for the persistence of living triploids in bisexual populations and to furnish a hypothesis on the origin of triploids. Moreover, the results will make it possible to furnish further information about the ploidy pattern of Bufo viridis, a species which is still not well defined and for which taxonomic problems exist (Liu et al., 2000). To give additional support to the karyological data, the ploidy level was evaluated as genome mass, and expressed in pg/nucleus, by flow cytometric analysis (FCM) of nuclear DNA content. This technique, successfully applied to a variety of taxa (Alfei et al., 1996; Cavallo et al., 1997, De Vita et al., 1994; Tiersch and Chandler 1991) allows the rapid and accurate quantitative evaluation of cellular DNA content in thousands of interphase cells for each measurement. Hence, the ploidy level and genome size of individuals can be rapidly assessed.

\section{MATERIALS AND METHODS}

\section{Samples}

Karyological and flow cytometric FCM analyses were performed on blood samples taken from 14 green toads (Bufo viridis) from 7 localities by means of heart puncture: Almaty (Kazakhstan) 2 males; Ily river (Kazakhstan) 1 male; Tulek (Kirgizstan) 1 male and 1 female; two reproductive places located near Kok-jar (Kirgizstan) indicated as Kok-jar I (2 males) and Kok-jar II (4 males); Moldavia 1 male; Sardinia (Italy) 2 males.

\section{Karyological analysis}

100-200 $\mu \mathrm{l}$ of whole blood from each specimen were added to two $\mathrm{ml}$ of MEM medium (Gibco) containing 20\% calf serum (Boehringer) and 3\% phytohaemagglutinin. Incubation took place for 96 hours at $25^{\circ} \mathrm{C}$. Growth was stopped by adding 20 $\mu \mathrm{l}$ of a colcemid solution at $10 \mu \mathrm{g} / \mathrm{ml}$, and cells were fixed with Carnoy's fixative (methanol:acetic acid, 3:1). The chromosomes were prepared using the standard air-drying technique and stained with 5\% Giemsa solution ( $\mathrm{pH} 7$ ). The C-banding was performed by Sumner's method (1972).

\section{Flow cytometric analysis}

100-200 $\mu \mathrm{l}$ of blood from each case were diluted in PBS and the technique of Krishan (1975), with modifications (Tiersch et al., 1989), was used for DNA staining. Human male lymphocytes were used to set up the flow cytometer before each batch of measurements. Erythrocytes of Bufo viridis from Sardinia, with known flow-cytometric DNA content, were used as internal reference cells and were stained together with the blood cells from $B$. viridis under study with $1 \mathrm{ml}$ of lysis-staining buffer containing propidium iodide. The samples were analysed using a PAS II flow cytometer (Partec, Munster, Germany). A total of at least $2.10^{4}$ events were accumulated for each histogram and the histograms were analysed using PAS/FLOW software. The coefficient of variation (CV) of fluorescent distributions ranged from 3 to $6 \%$. At least six measurements were performed for each specimen.

\section{RESULTS}

\section{Karyological analysis}

In specimens from Kok-jar I, Tulek, Moldavia and Sardinia, karyological analysis evidenced a diploid chromosome set with $2 \mathrm{n}=22$ biarmed chromosomes arranged in 11 pairs, of which the first six pairs were clearly longer than the other five; the pairs four, six and seven were submetacentric and the others metacentric. The four Kokjar II specimens showed a triploid chromosome set with 33 chromosomes arranged in 11 triplets similar in length and morphology to the corresponding pairs of diploid sets. The specimens from the Almaty and Ily river presented tetraploid chromosome sets with 44 biarmed chromosomes arranged in 11 quartets. All specimens (Fig.1) contained: heterochromatin in the centomeric region of all chromosomes; weak telomeric bands 
in the first six chromosome pairs, paracentromeric bands on the short arm of the first, second, third, fifth and sixth pairs, and on the long arm of the fourth and eighth pairs. This pattern was found in all the specimens studied, practically without considerable differences. The only detectable differences concerned the intensity of the C-bands. For example, the paracentromeric band on the long arm of the eighth chromosome was well evident in triploid and tetraploid karyotypes, but was faint in the diploid karyotype.

\section{Flow cytometric analysis}

In all cases, sufficiently good histograms with no significant differences between the repeated measurements [mean Standard Deviation (S.D.) value of 0.2, range 0.04-0.30] were obtained. Nuclear DNA content of the two diploid specimens (see karyological data) of B.viridis from Sardinia, evaluated with respect to the human lymphocyte cellular standard, was $8.0 \mathrm{pg} /$ nucleus. Using this cellular type as our internal standard, the value of FCM nuclear DNA content was expressed, for each case, as $\mathrm{pg} /$ nucleus relatively to the DNA value of 8.0 $\mathrm{pg} /$ nucleus, and represents the mean of six measurements. The specimens from Kokjar I, Tulek and Moldavia with DNA content ranging from 8.0$9.0 \mathrm{pg} /$ nucleus (overlapping standard diploid value) are thus interpreted as diploid populations. The specimens from Kok-jar II, with a DNA value of $12.0 \mathrm{pg}$ (diploid value half as much again) represent a triploid population. The specimens from the Almaty and Ily river, with DNA values ranging from 15.0 to $16.0 \mathrm{pg} /$ nucleus (approximately dou- ble with respect to the diploid standard value) represent tetraploid populations (Table 1).

\section{DISCUSSION}

\section{Inter-populational variability of genome size} against karyological uniformity

FCM analysis evidenced a DNA content variability of $1 \mathrm{pg} /$ nucleus inside diploid and tetraploid populations with respect to the same chromosome morphology and constitution. This result confirms the evidence coming from a similar analysis conducted by Borkin et al. (1986) in more than 22 populations of Eurasian green toads. By means of an analysis carried out in two related species, Pleuroderma thaul and Pleuroderma brachops, which share diploid chromosome number and morphology but differ greatly in genome size $(3.0 \mathrm{pg} /$ nucleus in the former and 10.3 in the latter), Schmid et al. (1993) suggested that variation in DNA amount and karyotype conservativeness is attained by homogeneous, symmetrical changes in the amounts of all classes of DNA sequences. In the populations of Bufo viridis examined here, independently of ploidy level, no significant variations in C-banding pattern were observed. Therefore, symmetrical changes of moderately repetitive and interspersed single-copy, but not of the highly repetitive sequences, could be involved in the genome variation (and diversification) observed inside the diploid and tetraploid populations of the Bufo viridis analysed.

Table I

Nuclear DNA content and ploidy of the green toad (Bufo viridis) populations studied

\begin{tabular}{llcccc}
\hline Source & Reproduction site & $\begin{array}{c}\text { Number of } \\
\text { subjects }\end{array}$ & $\begin{array}{c}\text { DNA content } \\
\text { (pg/nucleus) means } \\
\pm \text { SD of the values of } \\
\text { different subjects }\end{array}$ & Karyotype & Ploidy \\
\hline Kok-jar (Kirgizstan) & Kok-jar I & 2 & $8.0 \pm 0.2$ & $2 \mathrm{n}=22$ & Diploid \\
& Kok-jar II & 4 & $12.0 \pm 0.1$ & $3 \mathrm{n}=33$ & Triploid \\
Tulek (Kirgizstan) & Tulek & 2 & $9.0 \pm 0.2$ & $2 \mathrm{n}=22$ & Diploid \\
Almaty (Kazakhstan) & Almaty & 2 & $16.0 \pm 0.1$ & $4 \mathrm{n}=44$ & Tetraploid \\
Ily river (Kazakhstan) & Ily river & 1 & 15.0 & $4 \mathrm{n}=44$ & Tetraploid \\
Moldavia & Moldavia & 1 & 8.0 & $2 \mathrm{n}=22$ & Diploid \\
Sardinia & Sardinia & 2 & $8.0 \pm 0.1$ & $2 \mathrm{n}=22$ & Diploid \\
\hline
\end{tabular}



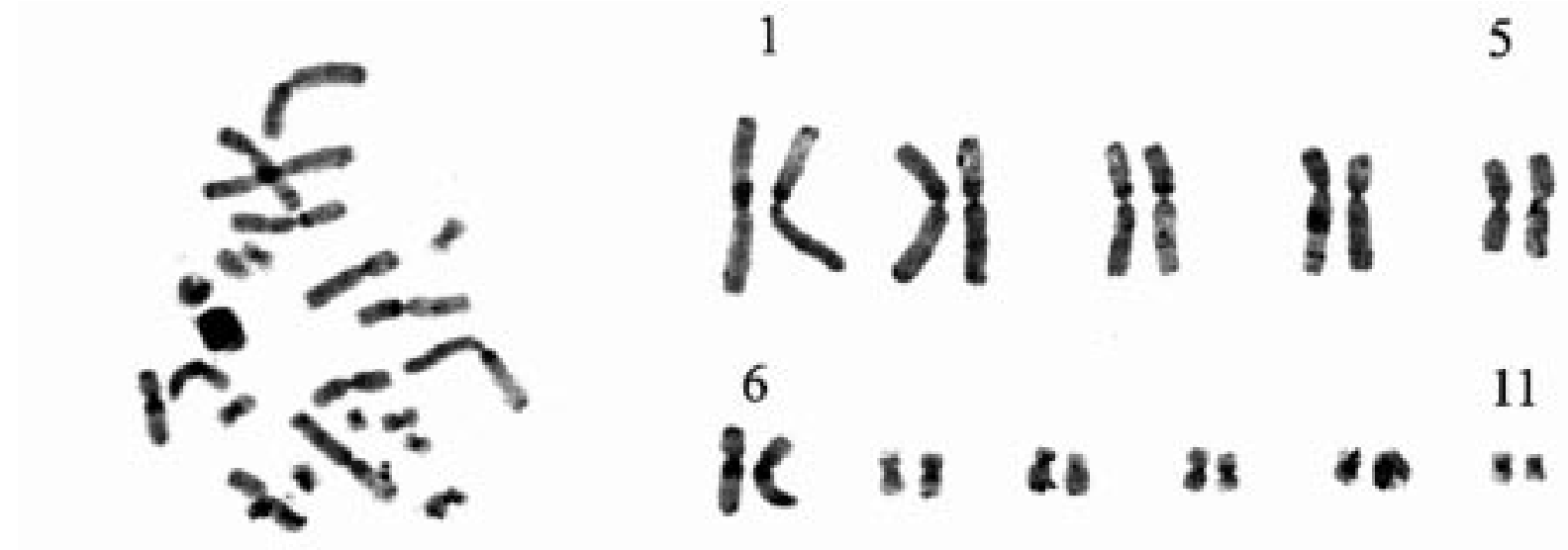

a 86350850
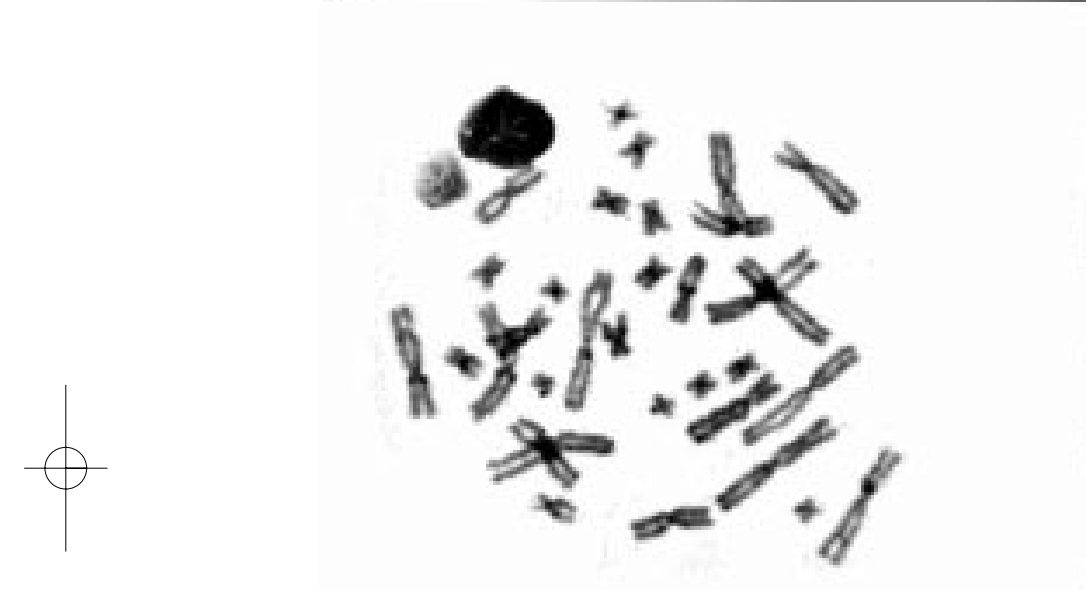

b
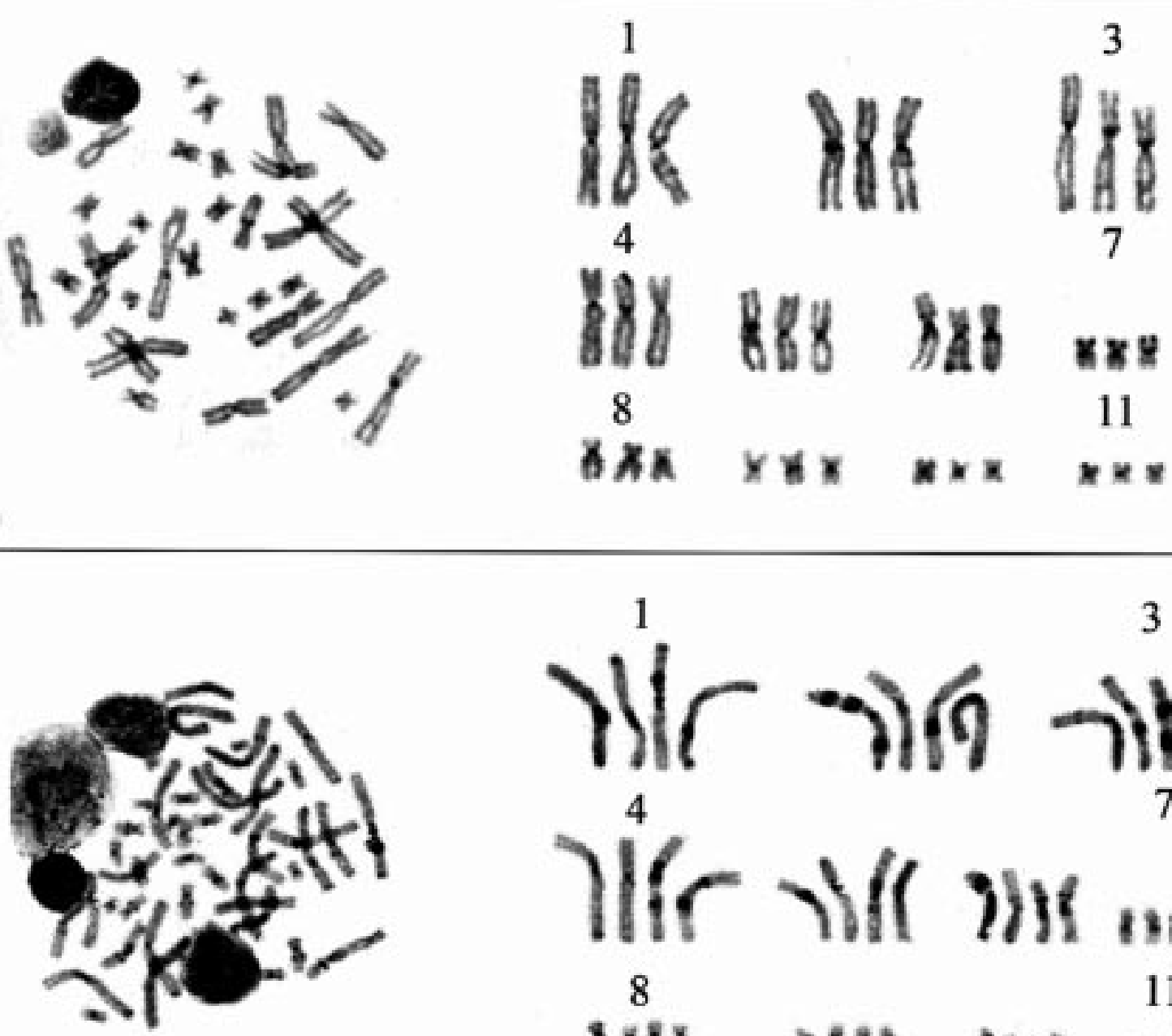

c
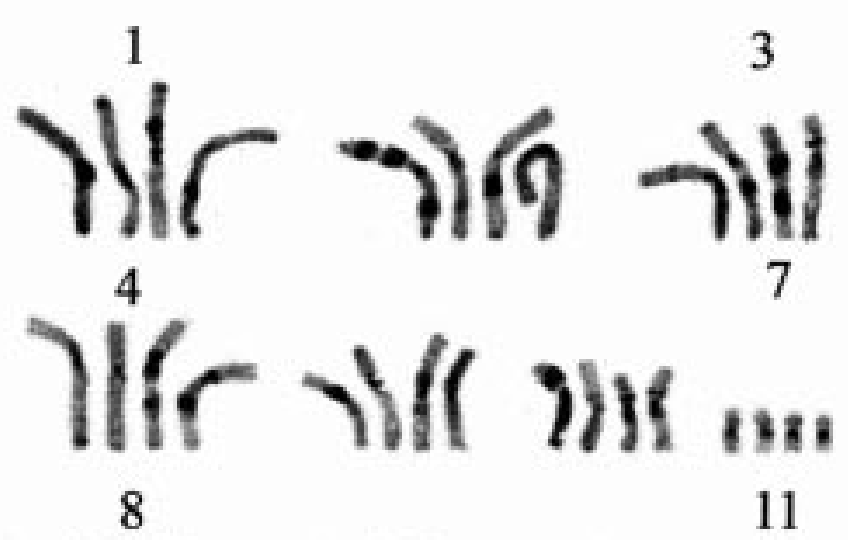

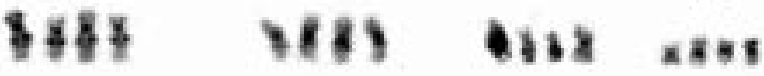

Fig. 1 - C-banded methaphase plates (on the left) and relative karyotypes (on the right) of: diploid (a), triploid (b) and tetraploid (c) specimens of the Bufo viridis complex. 


\section{Origin of polyploidy}

Our results confirm that no conclusion can be made about the origin of polyploidy in Bufo viridis. The uniformity of $\mathrm{C}$-banding pattern between diploid and tetraploid specimens seems to support an autoploid origin of polyploidy as evidenced by other studies performed by C-banding on more than 20 species of Bufo in which a distinctive karyological pattern, with the uniformity of both morphometric parameters and C-bands pattern between diploid and tetraploid populations of Bufo viridis, was shown (Birstein and Mazin, 1982; Matsui et al. 1995; Miura 1995). Otherwise, the diversification present in diploid populations of Bufo viridis without heterochromatin rearrangements, indicates that an origin of tetraploid population by allopolyploidy (through hybridization between two diversified diploid populations and subsequent duplication of two chromosome sets) cannot be ruled out.

\section{Triploidy}

FCM analysis, in agreement with karyological data, showed the presence of triploid specimens in the kok-jar II population evidencing a temporal continuity of triploids in a particular reproductive site. In fact, in a study performed in the kok-jar II place by Odierna et al. (1995) in the previous reproductive season, triploid specimens were found together with a small number of diploid and tetraploid specimens. The previously evidenced syntopy of diplo- and tetraploid specimens in the kok-jar II place, could support an intra-population hybrid origin of the triploids found in the present study. Alternatively, the triploids could arise because, due to environmental factors, the expulsion of a polar globule does not occur during the ovogenesis of diploid females, and the diploid ovocytes are then fertilized by haploid sperms. A further hypothesis could be that haploid ovocytes are fertilized by unreduced diploid sperms. In all cases, the optimal conditions for this seem to arise exclusively in this reproductive site. In fact, only diploid specimens were found in in the Kok-jar I reproductive site (located nearby to Kok-jar II place), and the other populations examined in this study resulted to be diploid or tetraploid. Furthermore, available data in the literature on Bufo viridis, in many of the other 60 reproductive places, always report the presence of diploid or tetraploid specimens (Pisanetz, 1978, 1991; Borkin et al. 1986; Roth and Rab, 1986). Triploid Bufo viridis specimens have been successfully attained by hybridization under experimental conditions (temperature shock or hydrostatic compression of eggs, which that inhibit the formation of the second polar body and subsequent fertilization with haploid sperm) (Bogart, 1972, Ferrier et al. 1978). Conversely, in natural bisexual populations, live triploid specimens were occasionally found both in Bufo (Bufo poweri) (Schmid, 1978) and in other taxa of Amphibia anura (Elinson 1993; Formas 1994). The presence of triploids in bisexual populations is normally considered inconsequential. In fact, due to anomalies arising during meiosis, the triploids are generally sterile (White 1973). The persistence and the high number of triploids evidenced in our study is therefore surprising. In this field, interesting data could be furnished by molecular cytogenetics. However, the present results show that FCM and karyological analyses can provide interesting data on the origin of polyploidy in the Bufo viridis complex and could furnish further information also on the origin of triploids if applied to germinal cells.

\section{REFERENCES}

Alfei L., Cavallo D., Eleuteri P., Colombari P.T., Ferri A., Onali A. and De Vita R.: Nuclear DNA content assessment in Salmo fibreni living in the italian lake of Posta Fibreno. J. Fish Biol. 48, 1051-1058, 1996.

Birstein V.I. and Mazin A.I.: Chromosomal polymorphism of Bufo bufo: karyotype and C banding pattern of B. b. verrucosissima. Genetica 59, 93-98, 1982.

Bogart J.P. Karyotypes. In: Evolution of the genus Bufo, W.F. Blair Ed, Univ. Texas press, Austin, London, pp. 171-195, 1972.

Borkin L.J., Caune I.A., Pisanetz E.M. and Rozanov Y.M.: Karyotype and genome size in the Bufo viridis group. In: Studies in herpetology, Rocek Ed., pp. 137-142, 1986.

Cavallo D., De Vita R., Eleuteri P. and Dell'Omo G.: Sex identification in the Egyptian vulture by flow cytometry and cytogenetics. Condor 99, 829-832, 1997.

De Vita R., Cavallo D., Eleuteri P. and Dell'Omo G.: Evaluation of interspecific DNA content variations and sex identification in Falconiformes and Strigiformes by flow cytometry. Cytometry 16, 346-350, 1994.

Elinson R.P.: Viable triploid hybrids between a large frog, Rana Catesbeiana, and a small one, Rana septentrionalis. Herpetol. Rev. 24, 46-47, 1993. 
Ferrier V., Jaylet A.: Induction of triploidy in the newt Pleurodeles waltlii by heat shock or hydrostatic pressure. Interpretation of the different types of ploidy using a chromosomal marker. Chromosoma 69, 47-63, 1978.

Formas R.J.: A triploid individual of the Cilean leptodactylid frog Eupsophus vertebralis. J Herpetol. 28, 394-395, 1994.

King M.: Amphibia Vol. 4: Chordata 2. In: Animal Cytogenetics. Bernard J., Caldicot G., Wales Eds. Berlin- Stuttgart, p. 100, 1990.

Krishan A.: Rapid flow cytofluorometric analysis of mammalian cell cycle by propidium iodide staining. J. Cell Biol. 66, 188-193, 1975.

Liu W., Lathrop A., Fu J., Yang D., Murphy R.W.: Phylogeny of East Asian bufonids inferred from mitochondrial DNA sequences (Anura: amphibia). Mol. Phylogenet. Evol. 14(3), 423-435, 2000.

Matsui M., Seto T., Kohsaka Y. and Borkin L.J.: Bearing of chromosome C-banding patterns on the classification of Eurasian toads of the Bufo bufo complex. Amphibia-Reptilia 6, 23-33, 1995.

Miura I.: Two differentiated groups of the Japanese toad, Bufo japonicus japonicus, demonstrated by C-banding analysis of chromosomes. Caryologia 48, 23-136, 1995.

Odierna G., Aprea G., Morescalchi A. and Balletto E.: Poliploidia nel "group" Bufo viridis Laurenti, 768 (Amphibia, Salentia). Atti $56^{\circ}$ Congresso Unione Zoologica Italiana, Reggio Calabria 2-7 ottobre 1995, pp. 90-91, 1995.

Olmo E.T., Capriglione T. and Odierna G.: Genome size evolution in vertebrates: trends and constraints. Comp. Biochem. Physiol. 92B, 447-453, 1989.

Pisanetz E.M.: On new polyploid species of the toads, Bufo danatensis. Psinatez sp. N. from Turkmenia. Dokl. Ukrain. Acad. Sci. 3B, 280-284, 1978.

Pisanetz E.M.: The new dates of karyology of Bufo viridis complex (Amphibia, Bufonidae) and the questions of the origin of Asiatic tetraploid toads. Herpetol. Res. Leningrad 4150, 1991.

Roth P.: An overwiew of the systematics of the Bufo viridis group in middle and central Asia. In: Studies in herpetology, Roceck ed., Prague, 1991, pp. 127-130, 1986.

Roth P. and Rab P.: Karyotype analysis of the Bufo viridis group: Systematic implication. In: Studies in herpetology, Roceck ed., Prague, pp. 131-136, 1986.

Schmid M.: Chromosome banding in Amphibia. I Constitutive heterochromatin and nucleolus organizer regions in Bufo and Hyla. Chromosoma 66, 361-388, 1978.

Schmid M.C., Steinlein, Feichtinger W. and Poot M.: Chromosome banding in Amphibia. XVIII. Karyotype evolution and genomic size variation in Pleuroderma (Anura, Leptodactilydae). Cytogenet. Cell Genet. 62, 42-48, 1993.

Sumner A.T.: A simple technique for demonstrating centromeric heterochromatin. Exp. Cell Res. 75, 304-306, 1972.
Tiersch T.R. Chandler R.W., Wachtel S.S. and Elias S.: Reference standards for flow cytometry and application in comparative studies of nuclear DNA content. Cytometry 10, 706710, 1989.

Tiersch T.R. and Chandler R.W.: On the evolution of genome size of birds. J. Hered. 82, 363-368, 1991.

White M.J.D.: Animal cytology and evolution. Cambridge University Press, VII +961, 1973. 